\title{
Cognitive skills of emergency medical services crew members: a literature review
}

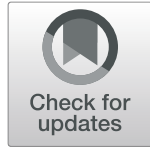

Martin Sedlári

\begin{abstract}
Background: Situation awareness and decision making, listed in non-technical skills taxonomies, are critical for effective and safe performance in high-risk professions. These cognitive skills and their behavioral markers have been studied less in emergency medical services (EMS) crew members. This paper aims to review the existing literature and identify important aspects and behavioral markers of situation awareness and decision making in EMS crew members - those who work in the role of prehospital emergency care providers - and to synthesize findings as a basis for developing a rating and training tool.

Method: The search for relevant articles was conducted using electronic databases, reference lists of relevant reviews and included articles and personal collection of articles. The selection process based on the PRISMA statement yielded a total of 30 articles that met the eligibility criteria. Their findings were qualitatively synthesized using the structured approach, informed by the already known structure: situation awareness and its elements (gathering information, interpreting information, anticipating future states), decision making and its elements (generating and considering options, selecting and implementing an option, reviewing outcome/decision). Moreover, the element of maintaining standards also emerged as highly relevant for cognitive skills.

Results: This review found an increased research interest in the non-technical cognitive skills of EMS crew members. The majority of included articles' research designs were qualitative, then mixed, Delphi, and quantitative. It revealed several specifics of cognitive skills, such as EMS crew members need to holistically assess a wide range of cues and information, to make various health- and safety-related decisions and take EMS standards into account. However, there was only a limited number of observable markers of cognitive skills, such as acts and verbalizations, that could be considered as examples of good behavior. In addition, findings indicate a lack of articles focused on mass-casualty incidents and the interconnection of cognitive skills with other non-technical and medical skills.
\end{abstract}

Conclusion: Further research is needed to get a more comprehensive view of behavioral markers of cognitive skills and to develop a rating and training tool to improve EMS crew members' cognitive performance.

Keywords: Emergency medical services, Ambulance, Prehospital, Non-technical skills, Cognitive skills, Situation awareness, Decision making, Literature review

Correspondence: martin.sedlar@savba.sk

Institute of Experimental Psychology, Centre of Social and Psychological Sciences, Slovak Academy of Sciences, Dúbravská cesta 9, 84104 Bratislava, Slovak Republic

(c) The Author(s). 2020 Open Access This article is licensed under a Creative Commons Attribution 4.0 International License, which permits use, sharing, adaptation, distribution and reproduction in any medium or format, as long as you give appropriate credit to the original author(s) and the source, provide a link to the Creative Commons licence, and indicate if changes were made. The images or other third party material in this article are included in the article's Creative Commons licence, unless indicated otherwise in a credit line to the material. If material is not included in the article's Creative Commons licence and your intended use is not permitted by statutory regulation or exceeds the permitted use, you will need to obtain permission directly from the copyright holder. To view a copy of this licence, visit http://creativecommons.org/licenses/by/4.0/. The Creative Commons Public Domain Dedication waiver (http://creativecommons.org/publicdomain/zero/1.0/) applies to the data made available in this article, unless otherwise stated in a credit line to the data. 


\section{Background}

Situation awareness and decision making are paramount for emergency medical services (EMS) crew members in encountering and managing various routine and nonroutine situations [1] with high stakes, complexity, dynamic changes, multiple stimuli, uncertainty, stress, and the high likelihood of being error-prone [2]. These cognitive skills are on the list of key non-technical skills. If they are satisfactory, they enable safe and quality prehospital emergency care [3-5]. Since human error is in the spotlight as the main contributing factor in poor safety outcomes [6], the significance of studying cognitive and other non-technical skills has become more apparent. It is demonstrated in skills taxonomies, behavior rating tools, and skills trainings [7-11].

Situation awareness, defined as knowing what is happening in the environment, is based on three elements: gathering information, interpreting information, and anticipating future states $[3,12]$. Sometimes the term 'situation awareness' interchanges with the term 'situation assessment' [13]. A comparison of theories suggests that both terms relate to the understanding of the situation and have analogical cognitive processes [12-14]. For that reason, these terms are here used together under the category of situation awareness. Considering the interconnection between situation awareness and decision making $[1,15]$, situation awareness is the foundation for decision making. The non-technical skills category of decision making - simply viewed as reaching a judgment or choosing an option - contains four elements: situation assessment/defining problem, generating and considering options, selecting and implementing an option, and outcome review [3]. As seen, decision making goes beyond the act of the decision itself and situation assessment represents the first step in making decisions [13].

The defined cognitive skills can be incorrectly confused with medical and technical skills. Although both skills are cognitive in their essence - requiring a form of cognitive activity - indeed they differ. Medical and technical skills refer to specific elements of medical diagnosis, treatment, and the physical procedures thereof [16]. In other words, they are about using medical expertise, drugs, and equipment [11]. In contrast, non-technical cognitive skills are conceptualized as general skills [17], referring to diverse situational elements that must be perceived, monitored, assessed, and decided upon, without the need for manual dexterity. Despite the difference, non-technical skills complement technical skills [3]. Besides, there is evidence of their correlation $[18,19]$.

Cognitive skills and their individual processes have been scrutinized predominantly in naturalistic decision making and expertise research [20]. In general, they are harder to be directly observable in behavior, compared with social skills, because they occur primarily in the brain. However, the non-technical skills movement, which emphasizes the behavioral level of skills, claims that situation awareness and decision making can be inferred from some observable behavior, such as specific actions and verbalizations [21].

So far, the existing literature summaries has not brought enough details about cognitive skills in EMS crew members, and not at all about their behavioral markers. This shows a paucity of research on nontechnical cognitive skills, expertise, and safety, which would assist in improving performance in the EMS field. Such research is also needed as each medical specialty has its specifics related to the personnel and work environment, and it is not correct to simply apply findings from one specialty to another.

This paper looks closer on cognitive skills, it aims to review the existing literature and identify important aspects and markers of situation awareness and decision making in EMS crew members - those who work in the role of prehospital emergency care providers - and to synthesize findings as a basis for developing a rating and training tool.

\section{Method}

\section{Search method}

This literature review utilized the Preferred Reporting Items for Systematic Reviews and Meta-Analysis (PRISMA) statement [22] and the Cochrane Handbook for Systematic Reviews of Interventions [23] to ensure methodological accuracy. Familiarization with the relevant literature on non-technical skills, naturalistic decision making, and expertise informed a process of creating the best search strategy, which would produce a limited number of irrelevant records and a multitude of relevant records. This process required the iterative cycle of searches using various synonyms and very close terms that were in line with the review aim. The final search strategy using Boolean operators contained the terms related to two main concepts: nontechnical cognitive skills of situation awareness and decision making, and EMS crew members. The search for relevant articles was conducted in December 2018, without any publication date limitations, using electronic databases and additionally by hand. More details about the search strategy and information sources are given in Table 1.

\section{Selection process}

Relevant articles had to meet the inclusion/exclusion criteria (see Table 1), encompassing key aspects and markers of non-technical cognitive skills applicable in EMS crew members. The first two criteria (articles written in English and peer-reviewed articles) were applied already in searching databases. The inclusion of only peer-reviewed articles was used as the quality indicator of articles. The search was limited to article titles and 
Table 1 Information sources, search strategy, and inclusion/exclusion criteria

\begin{tabular}{|c|c|c|}
\hline & \multicolumn{2}{|l|}{ Information sources } \\
\hline $\begin{array}{l}\text { Searching } \\
\text { electronic } \\
\text { databases }\end{array}$ & \multicolumn{2}{|c|}{$\begin{array}{l}\text { Scopus, Web of Science (Core Collection), Science Direct, EBSCO (MEDLINE, PsycINFO, CINAHL, Psychology and Behavioral Sciences } \\
\text { Complete), and ProQuest Central (Health and Medical Collection, Nursing and Allied Health Database, Psychology Database, Research } \\
\text { Library, Science Database) }\end{array}$} \\
\hline \multirow{2}{*}{$\begin{array}{l}\text { Hand- } \\
\text { searching }\end{array}$} & \multicolumn{2}{|c|}{ Reference lists of relevant reviews and included articles, and personal collection of articles } \\
\hline & \multicolumn{2}{|l|}{ Search strategy } \\
\hline $\begin{array}{l}\text { Non-technical } \\
\text { cognitive skills }\end{array}$ & \multicolumn{2}{|c|}{$\begin{array}{l}\text { ("non-technical" OR "nontechnical" OR "human factor*" OR "crew resource management" OR "crisis resource management" OR } \\
\text { "competenc*" OR "skill" OR "skills" OR "situation awareness" OR "situational awareness" OR "situation assessment" OR "situational } \\
\text { assessment" OR "sensemaking" OR "sense-making" OR "decision making" OR "decision-making") } \\
\text { AND }\end{array}$} \\
\hline \multirow[t]{2}{*}{$\begin{array}{l}\text { EMS crew } \\
\text { members }\end{array}$} & \multicolumn{2}{|c|}{$\begin{array}{l}\text { ("emergency medical service*" OR "paramedic*" OR "ambulance*" OR "prehospital" OR "pre-hospital" OR "out of hospital" OR "out-of- } \\
\text { hospital" OR "emergency technician*" OR "emergency practitioner*" OR "emergency medical technician*" OR "emergency care } \\
\text { practitioner*") }\end{array}$} \\
\hline & Inclusion criteria & Exclusion criteria \\
\hline Language & Articles written in English & Articles not written in English \\
\hline $\begin{array}{l}\text { Publication } \\
\text { type }\end{array}$ & $\begin{array}{l}\text { Peer-reviewed research articles, review articles, and conference } \\
\text { articles }\end{array}$ & $\begin{array}{l}\text { Book chapters, editorials, abstracts, commentaries, letters, gray } \\
\text { literature }\end{array}$ \\
\hline Population & $\begin{array}{l}\text { Articles containing data relevant to various EMS ambulance } \\
\text { members, such as paramedics, physicians, nurses, emergency } \\
\text { medical technicians, emergency care practitioners, providing } \\
\text { prehospital emergency care }\end{array}$ & $\begin{array}{l}\text { Articles containing data relevant only to EMS students, trainees, } \\
\text { drivers, pilots, trainers, teachers, supervisors, managers, and } \\
\text { professionals providing tactical, wilderness or hospital care }\end{array}$ \\
\hline Topic & $\begin{array}{l}\text { Articles containing data relevant to non-technical cognitive skills of } \\
\text { situation awareness and decision making }\end{array}$ & $\begin{array}{l}\text { Articles containing data relevant to technical skills and very } \\
\text { specific medical cases. }\end{array}$ \\
\hline Outcome & $\begin{array}{l}\text { Articles containing data about important aspects and markers of } \\
\text { good situation awareness and decision making }\end{array}$ & $\begin{array}{l}\text { Articles containing data only about the importance of situation } \\
\text { awareness and decision making, non-technical skills levels after } \\
\text { some interventions, association between non-technical skills } \\
\text { and other variables, and about all human, situational, and } \\
\text { organizational factors influencing performance. }\end{array}$ \\
\hline
\end{tabular}

abstracts, but this was not possible in each database (Web of Science allows searching only 'topics', which includes titles, abstracts, keywords together - the same applies to Science Direct). After importing records into the reference manager Mendeley and removing duplicates by software and by hand, titles and abstracts were screened, and full texts of potentially relevant articles were retrieved. Additional full-text articles were identified through other sources, i.e., reference lists of relevant reviews [4, 24-28] and included articles, and personal collection of articles. Two reviewers independently reviewed $30 \%$ of records and full texts for eligibility; disagreements were resolved by discussion. This served to eliminate biases and take a consensual view on the selection process. Keeping this view in mind, one reviewer reviewed the remaining records and full texts. Ultimately, the selection process, displayed in Fig. 1 with the PRISMA flow diagram by Moher et al. [29], yielded 30 relevant full-text articles that met the selection criteria.

\section{Data extraction and synthesis}

Data were extracted from full-text articles using a Microsoft Excel form with a pre-established list of data items with the following headings: first author and year, study location, design, sample, and relevant findings. The study location was derived from the first author's country and the sample consisted of the number of participants included in the analysis - not all persons contacted to participate or excluded before analysis.

The extraction and synthesis of relevant findings were based on the theory of non-technical skills categories and elements [3] and the structured approach originally developed for the data analysis from the Critical Decision Method [30]. At first, reading articles served for better understanding and familiarization. Then, findings from each article were extracted and categorized according to their relevance to situation awareness and its elements (gathering information, interpreting information, anticipating future states), and to decision making and its elements (generating and considering options, selecting and implementing an option, reviewing outcome/decision). Reading articles indicated that the element of maintaining standards, originally attributed to the category of leadership [3], is an integral part of cognitive skills. For that reason, findings relevant to this element were also extracted. In the next stage, specific aspects and markers of each cognitive skill and element were 


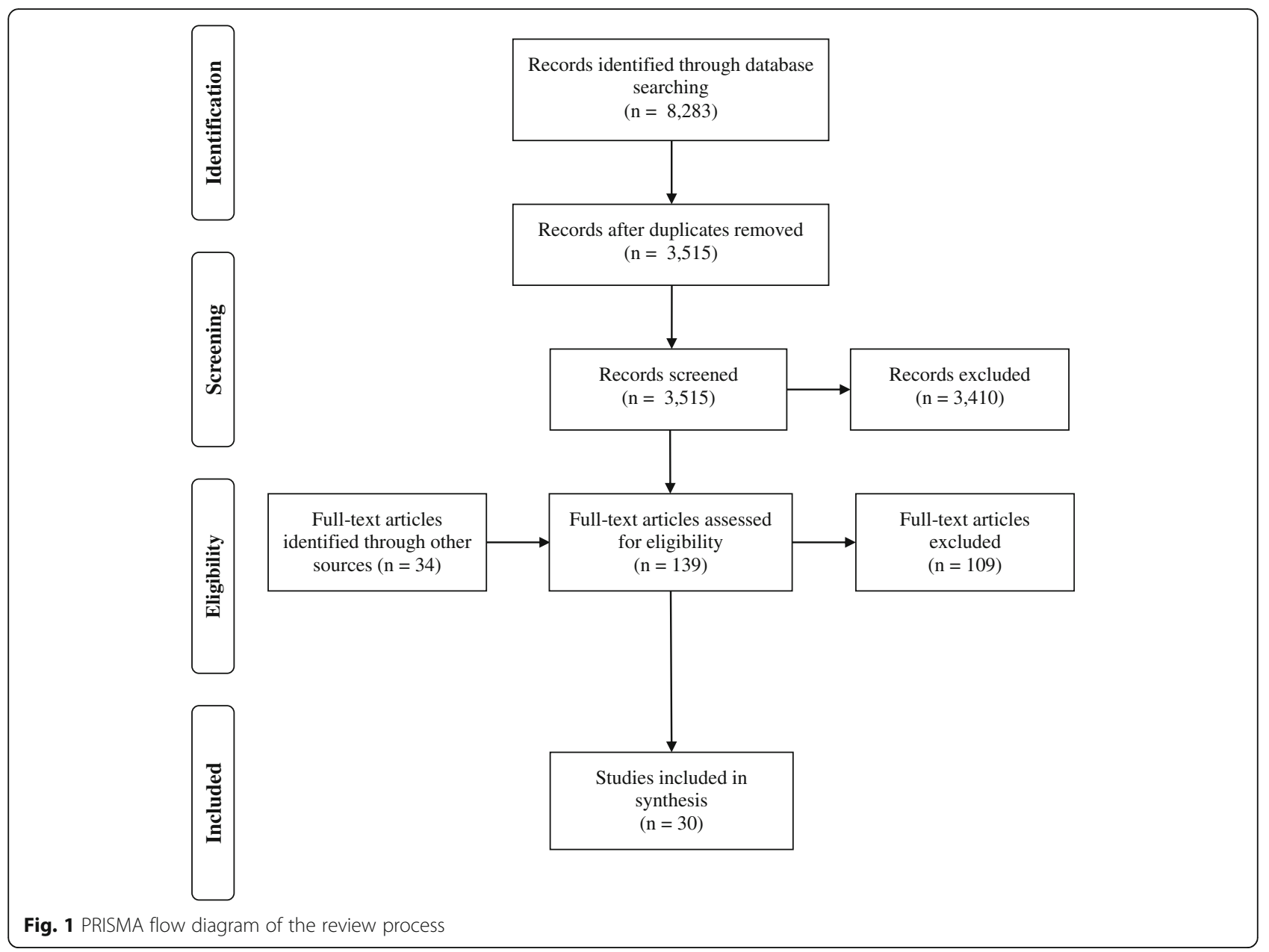

identified in each article. In the end, all relevant findings from all articles were integrated. The synthesis of findings was organized linearly for clarity, however, in real emergency situations, the situation awareness phase overlaps with the decision-making phase. Furthermore, it must be noted that the synthesis depends entirely on qualitative data. In the case of articles with quantitative or other designs, only their quantitative, descriptive parts were used.

\section{Results}

Of the 30 included research articles, the majority were qualitative in design $(n=17)$, then mixed $(n=5)$, Delphi $(n=5)$, and quantitative $(n=3)$. Their publication date ranged from 2003 to 2018 . The study locations were Sweden $(n=8)$, United States $(n=5)$, Canada $(n=5)$, Slovakia $(n=3)$, United Kingdom $(n=2)$, Australia $(n=$ $1)$, New Zealand $(n=1)$, Switzerland $(n=1)$, Norway $(n=1)$, Finland $(n=1)$, Iran $(n=1)$, and Taiwan $(n=1)$. The overview of the reviewed articles is given in Table 2 .

\section{Situation awareness}

The importance of developing a good awareness of a situation represents a common theme of many studies. Prehospital emergency situations, which can change very fast and at any moment, frequently require the development of situation awareness, both rapidly and on-the-spot [53], while synthesizing information about one's surroundings into a big picture/model of the situation [34, 43, 44, 47, 50, 54]. Reay et al. [47] highlights constructing a malleable/flexible model, determined to be continuously revised and adapted to a changing situation [59]. The synthesis combines information from focused assessments that are here separated, yet in EMS professionals' minds, they tend to overlap. The main assessment is focused on child or adult patients [42], and their various medical conditions and problems [31, 33, 37, 39-41, 47-51, 53, 57-59]. However, patients should not be taken only through the prism of medical issues, as they are individual human beings with different characteristics coming into play. Therefore, it is appropriate to assess them holistically, including their psycho-socio-economic-cultural background [33, 37, 39$41,48,49,53,55,57,58]$. In this process, EMS crew 


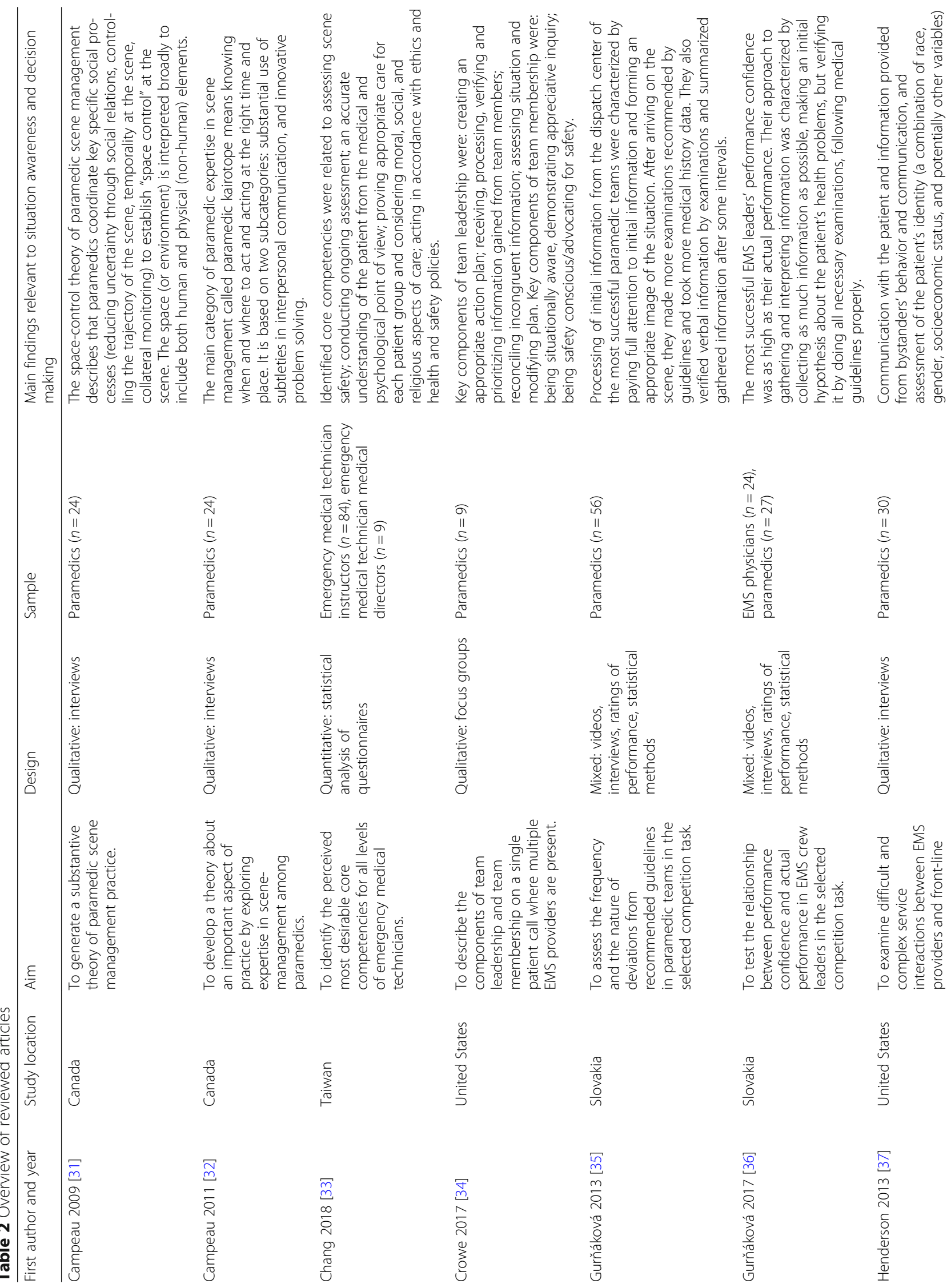




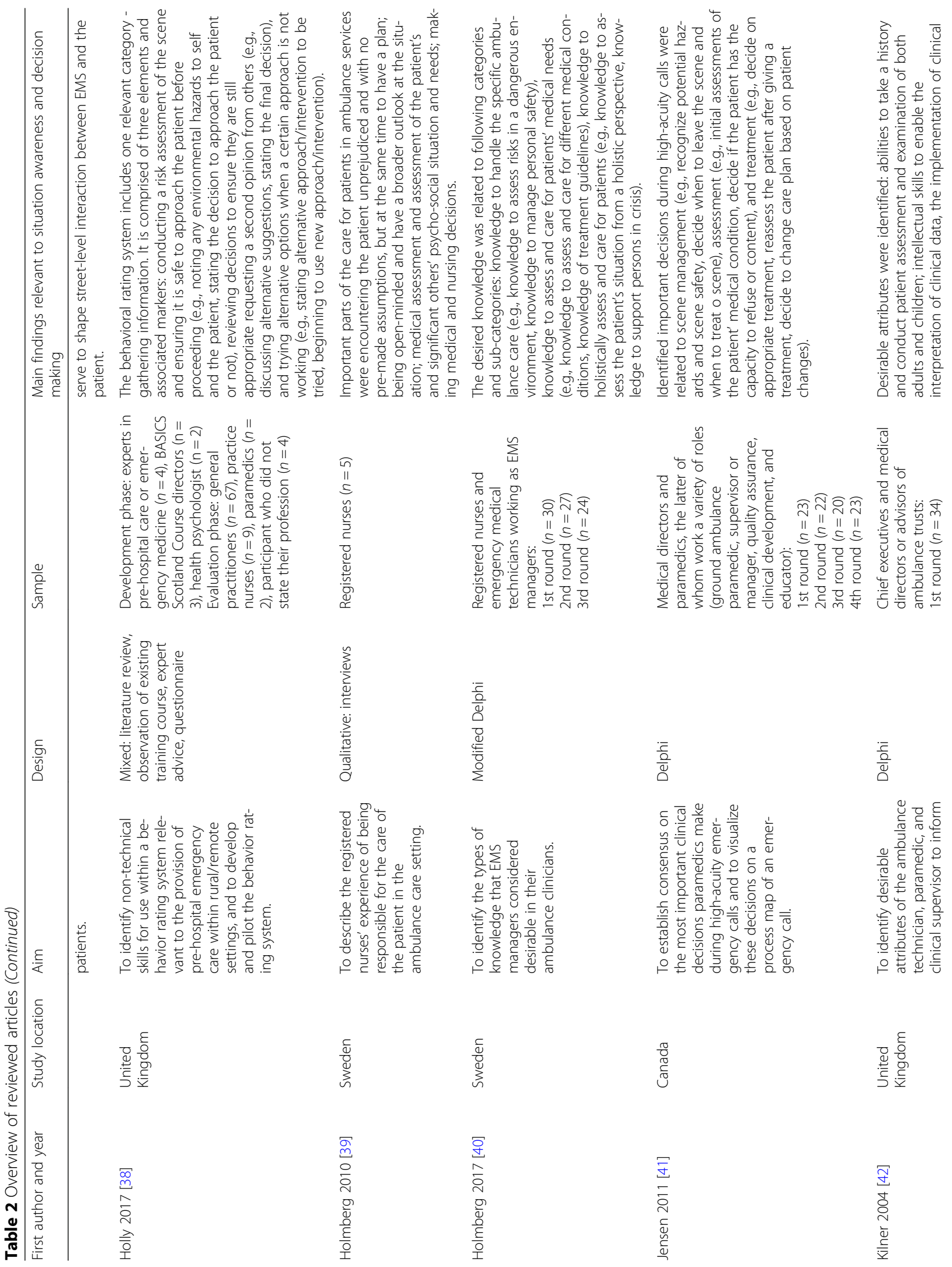




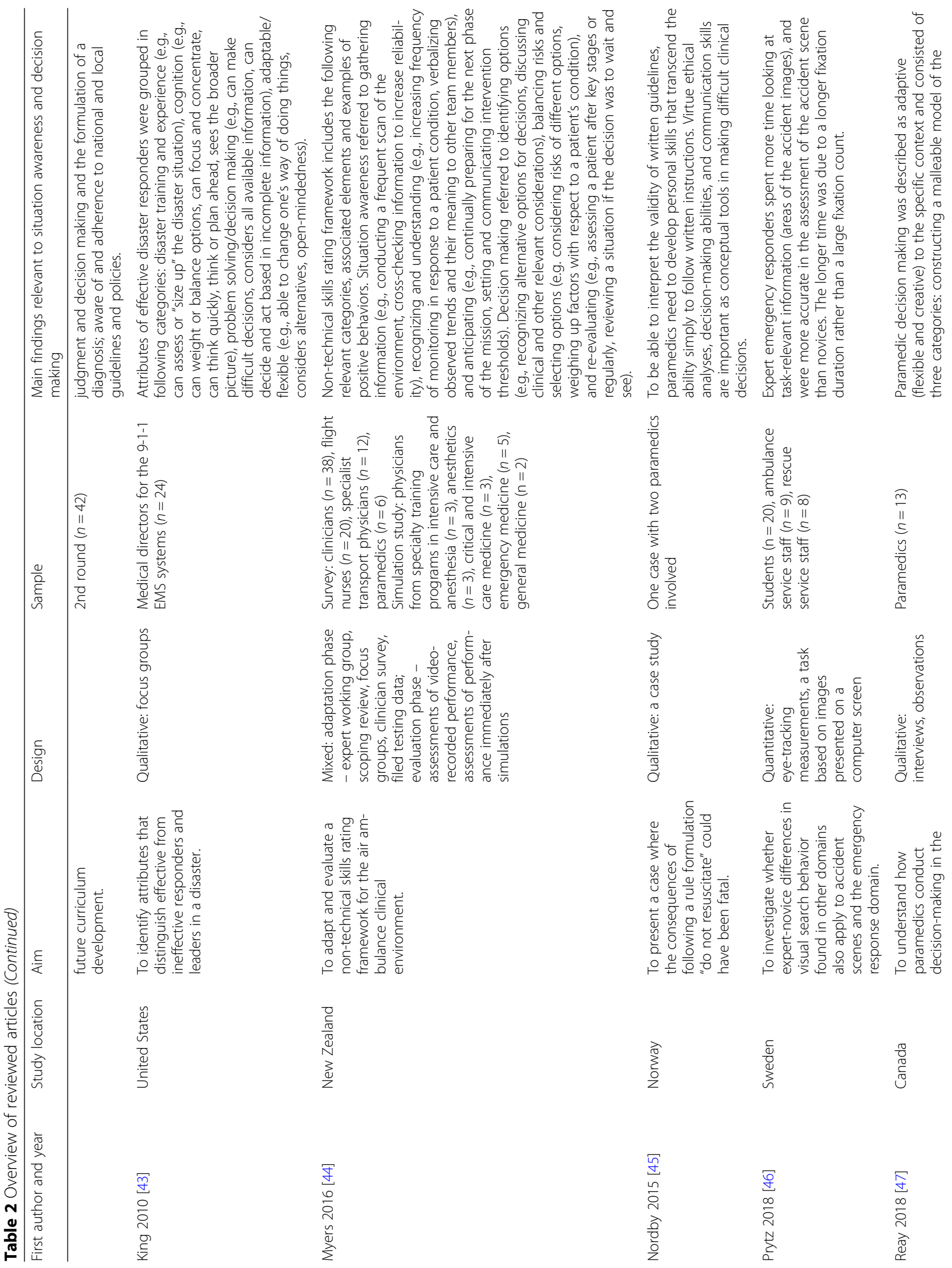




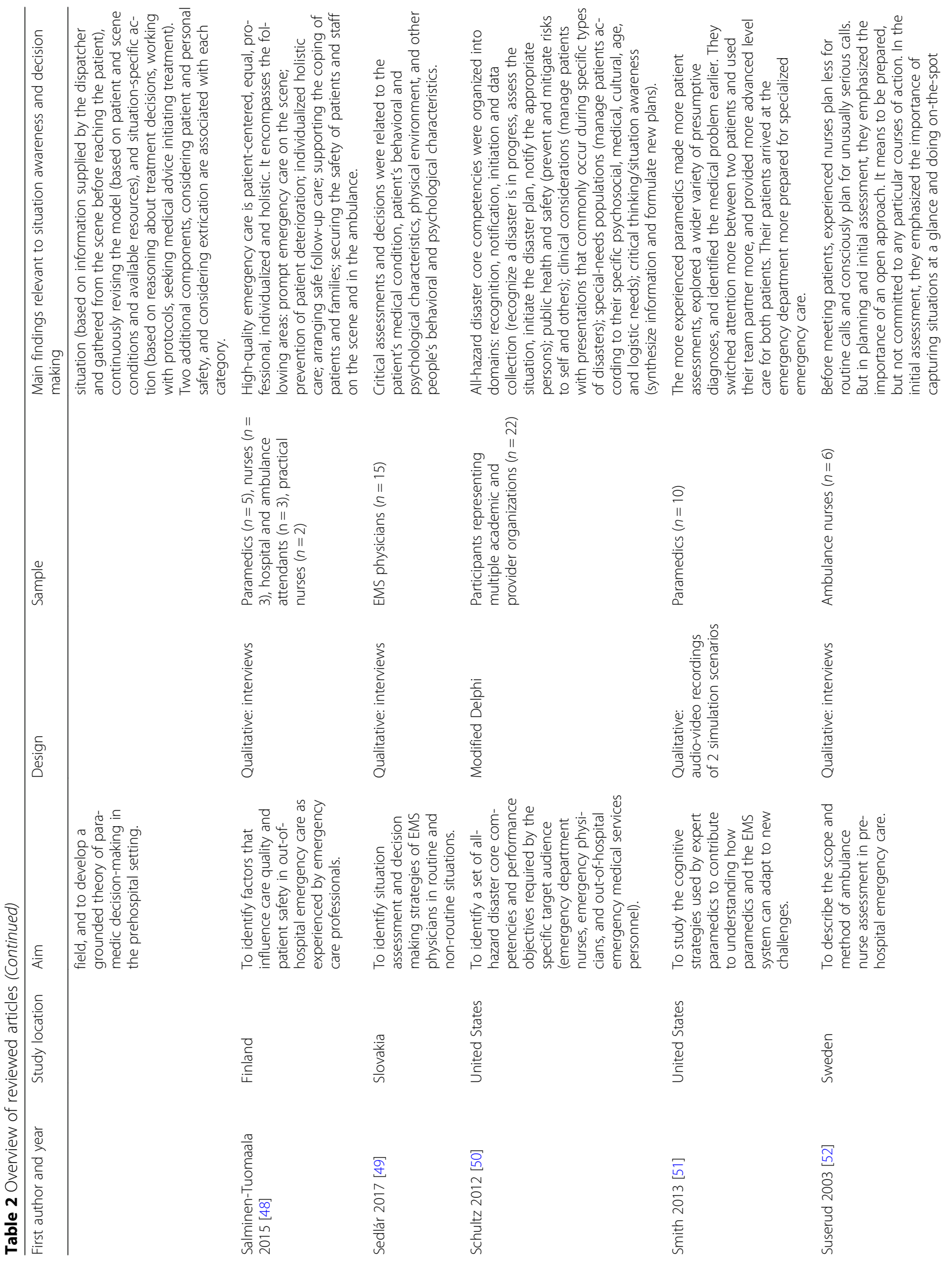




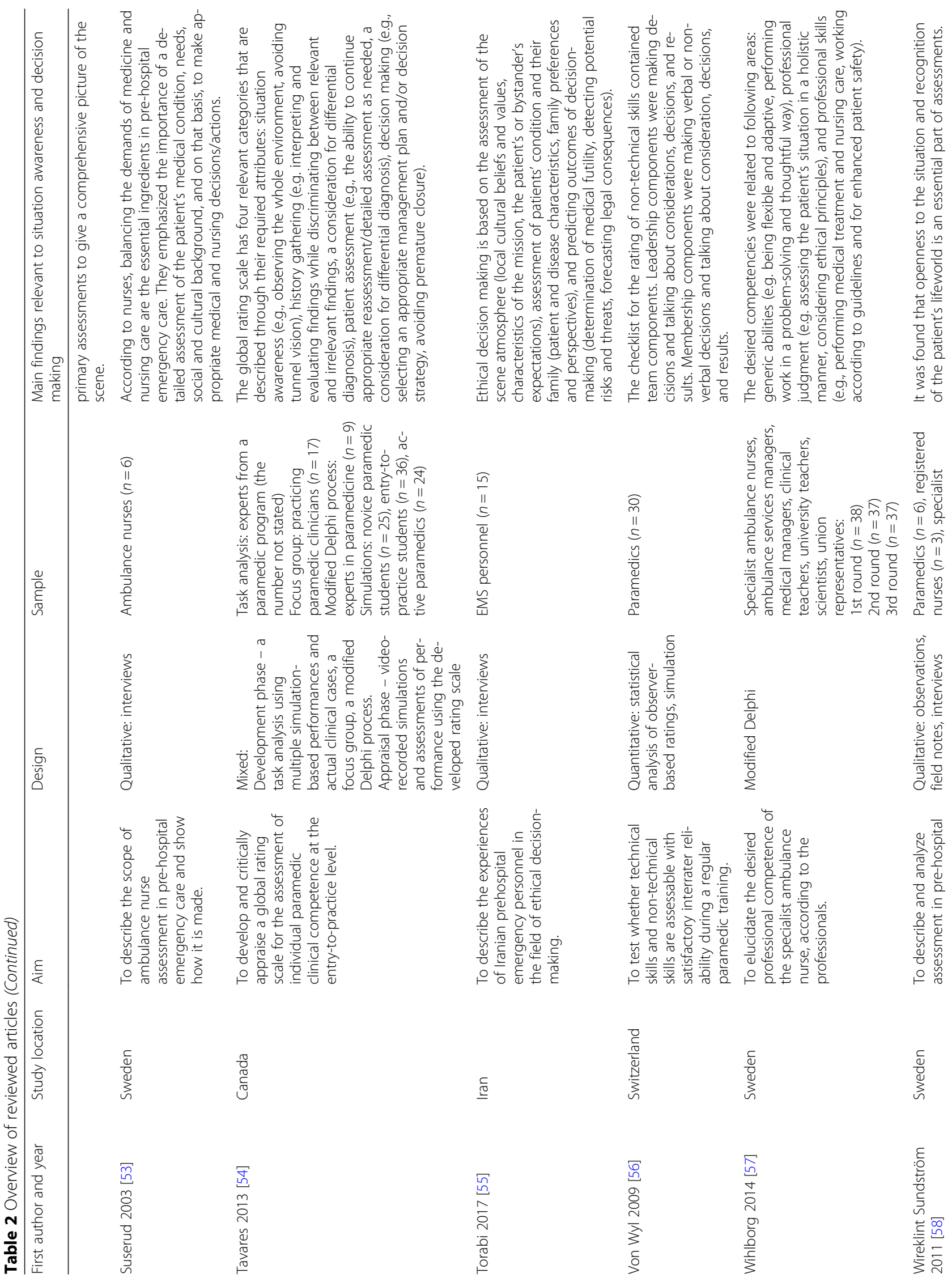




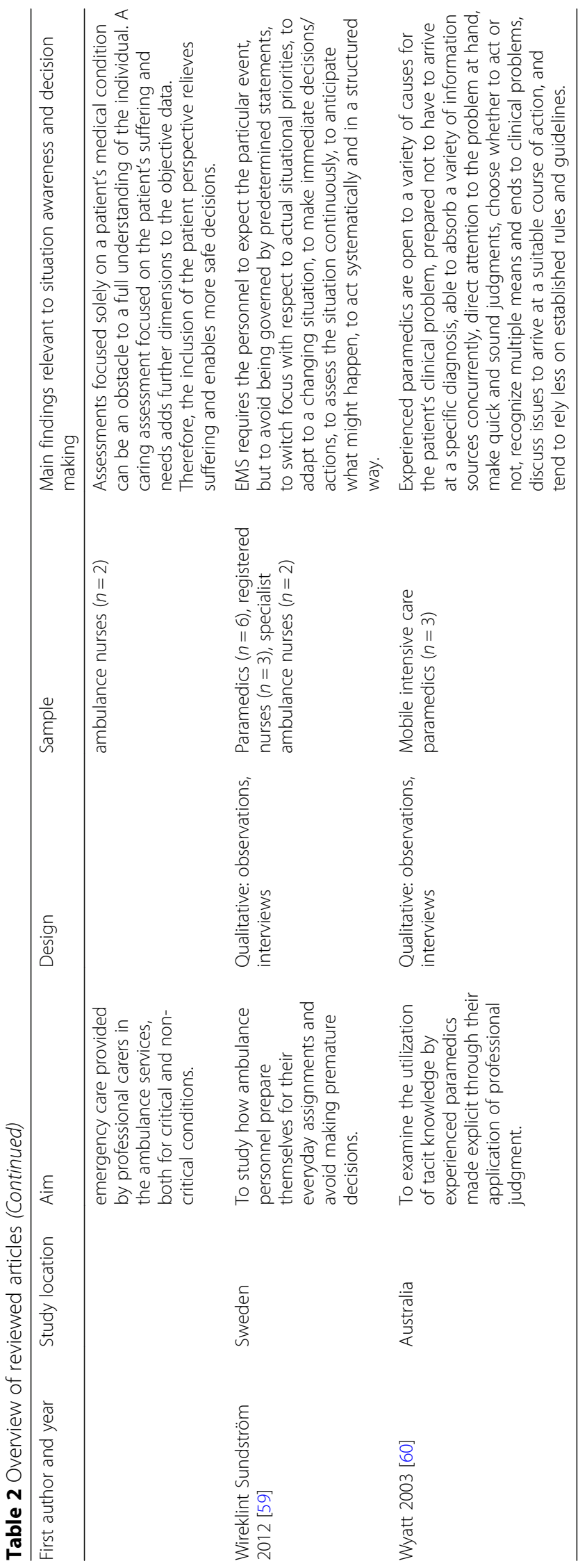


members should not neglect information from patients' significant others $[39,48,49,55]$. They can be valuable sources of information to manage the emergency situation to a satisfying conclusion. It also emerged that it was crucial for those in a high-risk EMS profession to assess the environment and the safety of patients, bystanders, and personnel on scene and in the ambulance [31, 33, 34, 38, $40,41,47,48,55,57]$. This means assessing clues and significant objects in the environment that can give a notion of what happens and to assess potential risks and threats.

\section{Gathering information}

During gathering information before arriving on the scene, it is emphasized to pay full attention to the initial information from the emergency dispatch center [35]. This can provide initial pertinent information to construct a malleable model of the call. As EMS crew members approach and enter the scene, looking for clues related to the patient's situation in the environment can add information to the model [47]. It is also important to observe the scene [54] and note (state) any environmental hazards to the self and the patient [38]. On the scene, the necessity is to focus and concentrate [43] what an expert can do quickly and directly to the problem at hand [60]. Usually, gathering information centers on history taking and physical examination of the patient [42], which should be conducted systematically [54, 57], promptly [41, 47, 48], effectively, thoroughly, appropriately to a given situation [54], and via perception and active/careful listening to information provided from the dialog with the patient $[35,36,59]$. Although the patient is a key information source, the information provided from bystanders' behavior and communication [37] is irreplaceable, especially when the patient is unconscious or unable to talk. However, the reliability of such information may not always be accurate. Other relevant markers of gathering information are discriminating between relevant and irrelevant data, avoiding tunnel vision [54], summarizing gathered information after some intervals [35], and verifying information to increase reliability [34, 44], e.g., checking verbally provided information by examination [35]. Furthermore, expertise research stresses the positive function of switching attention more between patients when more than one patient is involved [51] and spending more time looking at task-relevant areas of an accident [46]. Since emergency situations can change any minute, monitoring [31] or conducting a frequent scan of the environment [44] is crucial as a marker of good information gathering.

\section{Interpreting information}

Based on the collected information, EMS crew members made interpretations that are part of their mental model of the call. Although making good interpretations of patient's medical conditions is considered to be one of the required attributes [42, 57], it is critical to evaluate findings while discriminating between relevant and irrelevant data, avoid premature closure [54], rely less on the initial diagnostic hypothesis [51], and verify it by generating and exploring a wider variety of hypothetical diagnosis - differential diagnosis [33, 36, 51, 54]. Studies highlight being open to a variety of causes for the patient's clinical representation (to accept the general and not to have to arrive at a specific diagnosis) [60], the ability to absorb, process, and combine a variety of information and information sources simultaneously [35, 47, 60], and making quick, sound judgments [60]. When an element of incongruent information appears, the necessity is to reconcile information [34], or to look for consistency among various information sources and to question inconsistent variables [47]. More noticeable markers of good interpreting information are responding to changes in the patient's state, verbalizing observed trends and their meaning to other team members, increasing frequency of monitoring in response to patient condition [44], and interacting with team members that enable to correct potential misunderstanding [35].

\section{Anticipating future states}

Good situation awareness calls for anticipating what might happen: being aware of the probable scene trajectory $[31,43,54,55,59]$ and acting anticipatively [51, 60], which is necessary before and after arriving on the scene. In this regard, some kind of open-mindedness [43], or avoiding being governed by pre-made assumptions and prejudices, whilst at the same time expecting the known (usually the worst scenario) and the unexpected [39, 52, 58], seems substantial. Wireklint Sundström and Dahlberg [59] label this as being prepared for the unprepared, while Suserud et al. [52] calls it being prepared but not committed to any particular courses of action. Examples of positive behaviors related to anticipating future states are: keeping ahead of the situation with appropriate intervention, setting and communicating intervention thresholds, or continually preparing for the next phase of the mission [44].

\section{Decision making}

Included research articles mention making decisions/actions based on situation awareness, both rapidly [52, 59, $60]$ and systematically [59]. These decisions are primarily about medical treatment and management $[40,41,44$, 47], using various medical equipment, devices, and drugs, and occurring mostly with high density during the on-scene treatment phase of an emergency call [41]. Moreover, there are decisions made about the management of labor and delivery [41], nursing care and support $[39,40,48,53,57,58]$, deterioration prevention 
[48], extrication and transport [41, 44, 47], and safetyrelated decisions focused on preventing and mitigating risks of all persons involved [33, 40, 47, 48, 50, 57].

\section{Generating and considering options}

The next phase after understanding the nature of the situation and the patient's problem is called generating and considering options. The research found that experts recognize not only a suitable option or what needs to be done, but also when and where it needs to happen, using subtleties in interpersonal communication [32]. It may concern a decision about what treatment to initiate, and when and where to initiate it [47]. Furthermore, the studies revealed several important markers such as recognizing and considering multiple options to solve the problem [43, 60], considering risks and benefits [54] of different treatment and transport options, weighing up factors with respect to the patient's condition, assessing time criticality associated with possible options [44], and recognizing contraindications/reasons to withhold therapy [41]. More observable are markers such as seeking medical advice initiating treatment [47], seeking input on various transport-related issues with all relevant parties [44], and objectively evaluating and discussing clinical and other relevant considerations with team members $[44,56]$ to arrive at a suitable course of action [51]. These communication interactions occur more frequently in non-routine situations since courses of actions are already known in routine situations $[49,60]$.

\section{Selecting and implementing an option}

Selecting and implementing an option can be found in several articles that discuss the importance of selecting a safe, effective, situation-specific, appropriately prioritized and timed management plan and/or decision strategy $[33,34,47,54,56]$. The research highlights that experts can decide and act at the right time and place [32] based on incomplete information as emergency situations often require $[43,60]$. Overall, they provide care on an advanced level and prepare their patients better for specialized care in the emergency department [51]. Some identified positive markers of this decision making element are to state the decision to approach a patient (or not) depending on the assessment of the scene [38], request assistance from other authorities to ensure safety [48], establish a safe zone [31], to state other final decisions based on the discussed options, and to agree on these final decisions [38].

\section{Reviewing outcome/decision}

Another critical step in good decision making is to see how the situation has changed or if a decision was effective and led to desired results. In this sense, studies emphasize making more patient assessments, continuous assessments/reassessments of the patient, or reviewing the entire situation $[33,38,47,51,59]$. In particular, it is desirable when expectations are violated [37, 47, 54], after implementing a treatment plan [41], if the decision was to wait, after key stages of the transport or regularly [44]. Such reassessment informs EMS crew members about the patient's evolving condition and other (new) emerging information. This should be accompanied by making a list of options [44] and flexible changes in the course of action when needed [41,60]. When certain implemented options are not working, it is good to stop current intervention, state alternative approach/intervention, and begin to use a more appropriate course of action [38]. Some cases even require the ability to modify or create new courses of action [43] - a hallmark of expertise [32].

\section{Maintaining standards}

Included studies suggest an interconnection of maintaining standards with cognitive skills. Standards represent official structured methods of responding to emergency situations. They can be national, regional, and local guidelines, protocols and policies $[42,57]$, such as diagnostic guidelines $[36,48]$, treatment guidelines [40], advance directives [45], specific safety policies [33, 44], but also ethical principles and law [33, 42, 50, 55, 57]. These standards can guide situation awareness and decisionmaking processes. For instance, diagnostic guidelines may assist in gathering and interpreting information, and treatment guidelines and ethical principles help in making proper final treatment decisions. The authors mention the necessity of adherence to standards [42, 57], or at least knowing them [40] to consider and follow them when appropriate [33, 42, 44, 50, 55, 57]. At an EMS crew's competition, following diagnostic guidelines was found to be a key in the success and may eliminate the risk of selection bias [35, 36]. However, it must be said that the competition underlines primarily guidelinebased performance. According to Wyatt [60], as opposed to novices, experienced paramedics tend to rely less on guidelines and do not follow them uncritically and word for word. Instead, they interpret guidelines and situations through their prism of experience. Besides, trusting certain guidelines may have fatal consequences, so EMS crew members must develop personal skills that transcendent the ability simply to follow guidelines [45].

\section{Discussion}

In this literature review, key articles relevant to EMS crew members' situation awareness and decision making were synthetized. The results demonstrate an increase in the study of these skills in EMS crew members in recent years when compared to the first-ever non-technical skills review [4], which covered seven papers and 
brought only brief descriptions without any details regarding aspects and behavioral markers of cognitive skills. The interest in the reviewed topic is shown in articles targeting partial questions regarding cognitive skills, or articles trying to encompass all relevant non-technical skills or competencies essential for EMS crew members.

\section{Markers of cognitive skills}

Many articles discuss specific aspects relevant to the cognitive skills of EMS crew members, such as the need to holistically assess a wide range of cues and information, to make various health- and safety-related decisions, and to take EMS standards into account. However, only three articles developed rating tools containing behavioral markers of cognitive skills, such as specific acts and verbalizations, that could be considered as examples of good behavior. One focused solely upon air ambulance clinicians [44], one was developed for remote/rural settings prehospital care providers [38], and one mixed technical and non-technical categories into a rating scale of paramedic clinical competence with low observability of markers [54]. More articles described required competencies [33, 50, 57], attributes [42, 43], knowledge [40], and important decisions [41] or important aspects of cognitive work in the EMS setting [47, 59]. They primarily do not show behavioral markers, but essential aspects that should be reflected in performance. On the contrary, expertise research is rare according to the low number of included articles in the review, which resulted in the description of some characteristics of expert EMS professionals based on observations and performance ratings $[35,36,46,51]$. In this way, such obtained characteristics are similar to non-technical, behavioral rating systems. A study also proved the observability of a paramedic's expert performance during cardiopulmonary resuscitation, which was recognized based on the entire pattern of his behavior, the smoothness with which he works, and that it seems that he knows what he was doing [13]. This form of expertise represents accumulated experience and not following the rules usually taught to student paramedics. When it comes to the nature of the situation examined, only two articles are concerned with highly non-routine, masscasualty situations $[43,50]$. This alarmingly low incidence conflicts with high threats to patient safety, and the high importance of cognitive skills in such situations. The remainder of the articles points to the prevalence of examining situations with one or a few patients.

As suggested, even though each included article constitutes a piece in the jigsaw puzzle of aspects and markers of non-technical cognitive skills in EMS crews, there is still a need for research to fill in many blank spaces. Research questions should be asked to elicit positive behavior and expertise characteristics, as well as negative behavior, cognitive errors, and biases, and it should be particularly focused on situation awareness and decision making in routine and non-routine emergency situations. Such an approach can give a richer and deeper understanding of EMS crew members' cognition in its entirety and complexity.

\section{Interconnection of cognitive and other skills}

The relationships between cognitive skills and other skills were also revealed. At first, a link between situation awareness and decision making occurred implicitly or explicitly across many articles. One can say, situation awareness is fundamental since its quality directly affects the quality of decision making [15]. Second, maintaining standards commonly classified as the element of leadership [3] or task management [9] emerged as entering the situation awareness and decision-making processes, in which various forms of standards - such as guidelines or protocols - are followed or considered [36, 47]. Therefore, this element was included as an integral element of cognitive skills, just as in a crisis resource management rating scale, incorporating $\mathrm{ABC}$ protocol into the problem-solving skills category [61]. Third, the third level of situation awareness [12], projection, or anticipating future states seems to be very close to planning and preparing, as outlined in some papers [52, 59]. In this regard, Klein et al. [62] place the third level of situation awareness into a relationship with anticipatory thinking as a process of preparing for future events and distinguishes it from simply predicting what might happen. Fourth, there was an association of cognitive skills with some components of team leadership and membership $[34,56]$. Although the cognitive skills of leaders, as represented in the vast majority of articles, are more complex and demanding, sometimes other team members must switch their responsibilities with the leader's role as a result of team working. It means that all team members must develop the same cognitive skills, which is in line with team cognition markers that Salas et al. [63] united for all team members. Fifth, the findings suggested the necessity of good communication skills, used to gather information about the patient either through a dialog with the patient [35] or with other key informants [37, 47]. Communication interactions also help crew members to share and discuss information and considerations to arrive at a good understanding of the situation and decisions $[44,60]$. At last, history taking and physical examination conducted for the determination of a diagnosis [54], as rather medical skills, appeared in articles without specific information about how to do it from a purely medical point of view. However, they imply the significance of detailed patient assessment for situation awareness and decision making; hence, they were used in the review. These relationships are 
unsurprising, since non-technical skills are known to be close to one another and to medical and technical skills as well $[18,19]$. Unfortunately, precise descriptions of their mutual relations, influences and overlaps are rather scarce, representing another area that requires examination. An inspiration on the road to fill this research gap can be the visualization framework of macrocognitive functions, showing how they are interrelated and dynamically interacting [64].

\section{Limitations}

To make the research method and selection process rigorous, there was an exhaustive study of existing literature on the topic of cognitive skills and systematic reviews and the inclusion of more full texts to assess their eligibility, all to ensure any important paper has not been left out. The objectivity was promoted by the use of one independent rater for reviewing $30 \%$ of records and full texts, and the quality indicator of included articles applied already in database searches was the inclusion of peer-reviewed articles. However, these points may be viewed as a potential weakness of this literature review. A more critical approach would possibly bring slightly different findings. Further, the limitation is the exclusion of non-English articles, book chapters, and gray literature, which could add more relevant information. Strict selection criteria that restricted the capture of too specific aspects and all human, situational, and organizational factors that influence performance limits the results, yet the review did not have such an aim. If necessary, these issues could be inferred from the results gained here or addressed in future studies and reviews. It is also likely that some findings from related medical specialties are directly or after some adaptations applicable in EMS crew members; they were not included to keep the review as clear cut as possible. Orientation toward various EMS crew members (e.g., paramedics, emergency medical technicians, ambulance physicians, or ambulance nurses) can seem to be a misleading step. Nevertheless, to put them together was intentional because non-technical cognitive skills as general skills should apply essentially to all who work in the role of prehospital emergency care providers. Naturally, they usually need different specific medical and technical skills sets, depending on the prehospital setting (rural or urban) and health problem; this study is not about reviewing these skills. However, differences in the required level of training, skill sets and mandated interventions between EMS organizations in different countries can limit the generalizability and transferability of findings. That is why being prudent in the utilization of findings is recommended for researchers and practitioners.

\section{Conclusion}

To sum up, this review synthesized the body of literature on important aspects and behavioral markers of two non-technical cognitive skills of situation awareness and decision making in professionals who work in EMS crews throughout different countries. The results revealed an increased research interest in the issue of cognitive skills, several specifics relevant to the prehospital emergency setting, and the interconnection of cognitive skills with other skills categories. Most importantly, they indicate the need to examine cognitive skills further, since findings from included articles either had a limited number of observable markers or, overall, they were not comprehensive for EMS crew members. The research should be also conducted to develop a tool for assessing and training non-technical cognitive skills, which can consequently lead to the improvement of quality and safety in prehospital emergency care.

\section{Abbreviations \\ EMS: Emergency Medical Services; PRISMA: Preferred Reporting Items for Systematic Reviews and Meta-Analysis \\ Acknowledgements \\ I would like to thank my colleague Jitka Gurňáková for her help with the selection process. My gratitude also goes to reviewers Rein Ketelaars and Veronica Lindström for their constructive comments on the early version of this review article. This work was supported by the Scientific Grant Agency of the Ministry of Education, Science, Research and Sport of the Slovak Republic and the Slovak Academy of Sciences under Grant No. VEGA 2/0070/18.}

\section{Author's contributions \\ The author conducted the literature searches, screening, assessment of articles for eligibility, and synthesis processes. He was also the only contributor in writing the manuscript.}

\section{Funding}

This work was supported by the Scientific Grant Agency of the Ministry of Education, Science, Research and Sport of the Slovak Republic and the Slovak Academy of Sciences under Grant No. VEGA 2/0070/18. The agency did not participate in the design of the literature review, collection, synthesis, interpretation of data and writing the manuscript.

\section{Availability of data and materials}

All data generated and analyzed during this study are included in this review article. All articles included in this review article are available in relevant journals and proceedings.

\section{Ethics approval and consent to participate}

The entire Grant no. VEGA 2/0070/18 has been reviewed and received a Favorable Opinion from the Ethics Committee of the Slovak Academy of Sciences, Bratislava, Slovakia. A specific ethics approval was not needed for this review study.

\section{Consent for publication}

Not applicable.

\section{Competing interests}

No potential conflict of interest was reported by the author.

Received: 18 October 2019 Accepted: 29 April 2020

Published online: 29 May 2020

\section{References}

1. Keebler JR, Lazzara EH, Misasi P. Human factors and ergonomics of prehospital emergency care. Boca Raton: CRC Press; 2017. 
2. O'Connor RE, Slovis CM, Hunt RC, Pirrallo RG, Sayre MR. Eliminating errors in emergency medical services: realities and recommendations. Prehosp Emerg Care. 2002;6:107-13.

3. Flin $\mathrm{R}, \mathrm{O}^{\prime}$ Connor $\mathrm{P}$, Crichton M. Safety at the sharp end: a guide to nontechnical skills. Boca Raton: CRC Press; 2008.

4. Shields A, Flin R. Paramedics' non-technical skills: a literature review. Emerg Med J. 2013;30:350-4.

5. Bigham BL, Buick JE, Brooks SC, Morrison M, Shojania KG, Morrison LJ. Patient safety in emergency medical services: a systematic review of the literature. Prehosp Emerg Care. 2012;16:20-35.

6. Kohn LT, Corrigan J, Donaldson MS. To err is human: building a safer health system. Washington: National Academy Press; 2000

7. Batchelder AJ, Steel A, Mackenzie R, Hormis AP, Daniels TS, Holding N. Simulation as a tool to improve the safety of pre-hospital anaesthesia - a pilot study. Anaesthesia. 2009;64:978-83.

8. Govender K, Sliwa K, Wallis L, Pillay Y. Comparison of two training programmes on paramedic-delivered CPR performance. Emerg Med J. 2016;33:351-6.

9. Fletcher G, Flin R, McGeorge P, Glavin R, Maran N, Patey R. Rating nontechnical skills: developing a behavioural marker system for use in anaesthesia. Cogn Technol Work. 2004;6:165-71.

10. Jepsen RMHG, Østergaard D, Dieckmann P. Development of instruments for assessment of individuals' and teams' non-technical skills in healthcare: a critical review. Cogn Technol Work. 2014;17:63-77.

11. Fletcher GCL, McGeorge P, Flin RH, Glavin RJ, Maran NJ. The role of nontechnical skills in anaesthesia: a review of current literature. $\mathrm{Br} J$ Anaesth. 2002;88:418-29.

12. Endsley MR. Toward a theory of situation awareness in dynamic systems. Hum Factors. 1995;37:32-64.

13. Klein G. Sources of power: how people make decisions. Cambridge: MIT Press; 1998.

14. Klein $\mathrm{G}$. Analysis of situation awareness from critical incident reports. In: Endsley MR, Garland DJ, editors. Situation awareness analysis and measurement. Mahwah: Lawrence Erlbaum Associates; 2000. p. 51-71.

15. Strauch B. Investigating human error: incidents, accidents, and complex systems. 2nd ed. Boca Raton: CRC Press; 2017.

16. Gaba DM. Training and nontechnical skills: the politics of terminology. Simul Healthc. 2011:6:8-10.

17. Kodate N, Ross A, Anderson JE, Flin R. Non-technical skills (NTS) for enhancing patient safety: achievements and future directions. Jpn J Qual Saf Healthc. 2012;7:360-70.

18. Krage R, Zwaan L, Tjon Soei Len L, Kolenbrander MW, van Groeningen D, Loer SA, et al. Relationship between non-technical skills and technical performance during cardiopulmonary resuscitation: does stress have an influence? Emerg Med J. 2017;34:728-33.

19. Riem N, Boet S, Bould MD, Tavares W, Naik VN. Do technical skills correlate with non-technical skills in crisis resource management: a simulation study. Br J Anaesth. 2012;109:723-8

20. Ericsson KA, Hoffman RR, Kozbelt A, Williams AM. The Cambridge handbook of expertise and expert performance. 2nd ed. Cambridge: Cambridge University Press; 2018.

21. Flin R, Martin L, Goeters K-M, Hörmann H-J, Amalberti R, Valot C, et al. Development of the NOTECHS (non-technical skills) system for assessing pilots' CRM skills. Hum Factors Aerospace Saf. 2003;2:97-119.

22. Moher D, Shamseer L, Clarke M, Ghersi D, Liberati A, Petticrew M, et al. Preferred reporting items for systematic review and meta-analysis protocols (PRISMA-P) 2015 statement. Syst Rev. 2015:4:1.

23. Higgins JPT, Green S. Cochrane handbook for systematic reviews of interventions. Chichester: Wiley; 2008.

24. Carter H, Thompson J. Defining the paramedic process. Aust J Prim Health. 2015;21: 22-6.

25. Chang Y-T, Tsai K-C, Williams B. What are the educational and curriculum needs for emergency medical technicians in Taiwan? A scoping review. Adv Med Educ Pract. 2017:8:649-67.

26. Evans R, McGovern R, Birch J, Newbury-Birch D. Which extended paramedic skills are making an impact in emergency care and can be related to the UK paramedic system? A systematic review of the literature. Emerg Med J. 2014;31:594-603.

27. Tavares W, Bowles R, Donelon B. Informing a Canadian paramedic profile: framing concepts, roles and crosscutting themes. BMC Health Serv Res. 2016;16:477

28. Wireklint Sundström B, Bremer A, Lindström V, Vicente V. Caring science research in the ambulance services: an integrative systematic review. Scand J Caring Sci. 2019;33:3-33.
29. Moher D, Liberati A, Tetzlaff J, Altman DG, The PG. Preferred reporting items for systematic reviews and meta-analyses: The PRISMA statement. PLoS Med. 2009;6:e1000097.

30. Wong BW. Critical decision method data analysis. In: Diaper D, Stanton N editors. The handbook of task analysis for human-computer interactions. Mahwah: Lawrence Erlbaum Associates; 2003. p. 327-46.

31. Campeau A. Introduction to the "space-control theory of paramedic scene management". Emerg Med J. 2009;26:213-6.

32. Campeau A. The paramedic kairotope theory: findings. J Paramedic Practice. 2011:3:376-80.

33. Chang Y-T, Tsai K-C, Williams B. Development of new core competencies for Taiwanese emergency medical technicians. Adv Med Educ Pract. 2018;9: $147-58$

34. Crowe RP, Wagoner RL, Rodriguez SA, Bentley MA, Page D. Defining components of team leadership and membership in prehospital emergency medical services. Prehosp Emerg Care. 2017;21(5):645-51.

35. Gurňáková J, Harenčárová H. How is the diagnosis made? The observation of paramedics performance in simulated competition task. In: Chaudet $\mathrm{H}$, Pellegrin L, Bonnardel N, editors. Naturalistic decision making 2013: proceedings of the 11 th international conference on naturalistic decision making; 2013 may 21-24; Marseille, France. Paris: Arpege Science Publishing; 2013. p. 207-10

36. Gurňáková J, Sedlár M, Gröpel P. Who is the champion? Performance confidence and actual performance among emergency medical services crew leaders. In: Gore J, Ward P, editors. Naturalistic decision making and uncertainty: proceedings of the 13th bi-annual international conference on naturalistic decision making; 2017 Jun 20-23; Bath, UK. Bath: The University of Bath; 2017. p. 217-20.

37. Henderson AC. Patient assessment in emergency medical services: complexity and uncertainty in street-level patient processing. J Health Hum Serv Adm. 2013;35:505-42

38. Holly D, Swanson V, Cachia P, Beasant B, Laird C. Development of a behaviour rating system for rural/remote pre-hospital settings. Appl Ergon. 2017:58:405-13.

39. Holmberg M, Fagerberg I. The encounter with the unknown: nurses lived experiences of their responsibility for the care of the patient in the Swedish ambulance service. Int J Qualitative Stud Health Well-being. 2010;5:5098.

40. Holmberg M, Fagerberg I, Wahlberg AC. The knowledge desired by emergency medical service managers of their ambulance clinicians - a modified Delphi study. Int Emerg Nurs. 2017;34:23-8.

41. Jensen JL, Croskerry P, Travers AH. Consensus on paramedic clinical decisions during high-acuity emergency calls: results of a Canadian Delphi study. Can J Emerg Med Care. 2011;13:310-8.

42. Kilner T. Educating the ambulance technician, paramedic, and clinical supervisor: using factor analysis to inform the curriculum. Emerg Med J. 2004;21:379-85.

43. King RV, North CS, Larkin GL, Downs DL, Klein KR, Fowler RL, et al. Attributes of effective disaster responders: focus group discussions with key emergency response leaders. Disaster Med Public Health Prep. 2010;4(4):332-8.

44. Myers JA, Powell DMC, Psirides A, Hathaway K, Aldington S, Haney MF. Nontechnical skills evaluation in the critical care air ambulance environment: introduction of an adapted rating instrument - an observational study. Scand J Trauma Resusc Emerg Med. 2016;24:24.

45. Nordby $\mathrm{H}$. The importance of reliable information exchange in emergency practices: a misunderstanding that was uncovered before it was too late. BMC Med Ethics. 2015;16:46.

46. Prytz EG, Norén C, Jonson CO. Fixation differences in visual search of accident scenes by novices and expert emergency responders. Hum Factors. 2018;60:1219-27.

47. Reay G, Rankin JA, Smith-Macdonald L, Lazarenko GC. Creative adapting in a fluid environment: an explanatory model of paramedic decision making in the pre-hospital setting. BMC Emerg Med. 2018;18:42.

48. Salminen-Tuomaala M, Leikkola P, Paavilainen E. Emergency health care professionals' experiences of factors that influence care quality and safety. Clin Nurs Stud. 2015;3:30-68

49. Sedlár M. Situation assessment and decision making strategies of emergency medical services physicians in routine and non-routine situations. Stud Psychol. 2017:59:127-38.

50. Schultz CH, Koenig KL, Whiteside M, Murray R. Development of national standardized all-hazard disaster core competencies for acute care physicians, nurses, and EMS professionals. Ann Emerg Med. 2012;59:196-208. 
51. Smith MW, Bentley MA, Fernandez AR, Gibson G, Schweikhart SB, Woods DD. Performance of experienced versus less experienced paramedics in managing challenging scenarios: a cognitive task analysis study. Ann Emerg Med. 2013:62:367-79.

52. Suserud BO, Bruce K, Dahlberg K. Initial assessment in ambulance nursing: part one. Emerg Nurse. 2003;10(10):13-7.

53. Suserud BO, Bruce K, Dahlberg K. Ambulance nursing assessment: part two. Emerg Nurse. 2003;11(1):14-8.

54. Tavares W, Boet S, Theriault R, Mallette T, Eva KW. Global rating scale for the assessment of paramedic clinical competence. Prehosp Emerg Care. 2013; 17:57-67.

55. Torabi M, Borhani F, Abbaszadeh A, Atashzadeh-Shoorideh F. Ethical decision-making based on field assessment: the experiences of prehospital personnel. Nurs Ethics. 2019;26:1075-86.

56. Von Wyl T, Zuercher M, Amsler F, Walter B, Ummenhofer W. Technical and non-technical skills can be reliably assessed during paramedic simulation training. Acta Anaesthesiol Scand. 2009;53:121-7.

57. Wihlborg J, Edgren G, Johansson A, Sivberg B. The desired competence of the Swedish ambulance nurse according to the professionals - a Delphi study. Int Emerg Nurs. 2014;22:127-33.

58. Wireklint Sundström B, Dahlberg K. Caring assessment in the Swedish ambulance services relieves suffering and enables safe decisions. Int Emerg Nurs. 2011;19:113-9.

59. Wireklint Sundström B, Dahlberg K. Being prepared for the unprepared: a phenomenology field study of Swedish prehospital care. J Emerg Nurs. 2012;38:571-7.

60. Wyatt A. Paramedic practice - knowledge invested in action. J Emerg Prim Health Care. 2003;1:990057

61. Kim J, Neilipovitz D, Cardinal P, Chiu M, Clinch J. A pilot study using highfidelity simulation to formally evaluate performance in the resuscitation of critically ill patients: The University of Ottawa critical care medicine, highFidelity simulation, and crisis resource management I study. Crit Care Med. 2006:34:2167-74

62. Klein G, Snowden D, Pin CL. Anticipatory thinking. In: Mosier KL, Fisher UM editors. Informed by knowledge: expert performance in complex situations. New York: Psychology Press; 2011. p. 235-46.

63. Salas E, Rosen MA, Burke CS, Nicholson D, Howse WR. Markers for enhancing team cognition in complex environments: the power of team performance diagnosis. Aviat Space Environ Med. 2007;78:B77-85.

64. Patterson ES, Hoffman RR. Visualization framework of macrocognition functions. Cogn Technol Work 2012;14:221-7.

\section{Publisher's Note}

Springer Nature remains neutral with regard to jurisdictional claims in published maps and institutional affiliations.

Ready to submit your research? Choose BMC and benefit from:

- fast, convenient online submission

- thorough peer review by experienced researchers in your field

- rapid publication on acceptance

- support for research data, including large and complex data types

- gold Open Access which fosters wider collaboration and increased citations

- maximum visibility for your research: over $100 \mathrm{M}$ website views per year

At BMC, research is always in progress.

Learn more biomedcentral.com/submissions 